\title{
Структура и фотоэлектрические свойства пленок PbSe, осажденных в присутствии аскорбиновой кислоты
}

\author{
(С) Л.Н. Маскаева ${ }^{1,2}$, В.М. Юрк ${ }^{1}$, В.Ф. Марков ${ }^{1,2}$, М.В. Кузнецов ${ }^{3}$, В.И. Воронин ${ }^{4}$, О.А. Липина ${ }^{3}$ \\ ${ }^{1}$ Уральский фредеральный университет им. первого Президента России Б.Н. Ельцина, \\ 620002 Екатеринбург, Россия \\ 2 Уральский институт Государственной противопожарной службы МЧС России, \\ 620062 Екатеринбург, Россия \\ ${ }^{3}$ Институт химии твердого тела Уральского отделения Российской академии наук, \\ 620990 Екатеринбург, Россия \\ ${ }^{4}$ Институт фризики металлов им. М.Н. Михеева Уральского отделения Российской академии наук, \\ 620108 Екатеринбург, Россия \\ E-mail:mln@ural.ru
}

Поступила в Редакцию 13 апреля 2020 г.

В окончательной редакции 16 апреля 2020 г.

Принята к публикации 25 апреля 2020 г.

\begin{abstract}
Методами рентгеновской дифракции, растровой электронной микроскопии с элементным анализом, рентгеновской фотоэлектронной спектроскопии исследованы тонкие пленки $\mathrm{PbSe}$, полученные гидрохимическим осаждением с использованием в качестве антиоксиданта селеномочевины аскорбиновой кислоты. Изучено влияние температуры отжига на их элементный, фазовый состав, параметры кристаллической решетки, морфологию поверхности и фотоэлектрические свойства. Установлено, что после отжига при 633-683 K пленки содержат в своем составе примесные фазы $\mathrm{PbSeO}_{3}, \mathrm{PbSeO}_{4}, \mathrm{PbI}_{2}$. Определена оптическая ширина запрещенной зоны $E_{g}$ слоев при непрямом и прямом переходах. Показано, что по своим пороговым фотоэлектрическим характеристикам осажденные пленки сопоставимы с известными коммерческими образцами и могут быть использованы для создания высокочувствительных ИК-детекторов.
\end{abstract}

Ключевые слова: химическое осаждение, тонкие пленки, селенид свинца, термосенсибилизация, фоточувствительные свойства.

DOI: 10.21883/FTP.2020.10.49935.9411

\section{1. Введение}

Тонкопленочный селенид свинца $\mathrm{PbSe}$ - базовый полупроводниковый материал с относительно узкой запрещенной зоной $(0.27$ эВ при $300 \mathrm{~K})$, обладающий термоэлектрическими свойствами, а также фоточувствительностью и люминесценцией в ИК-диапазоне (1-6 мкм), поэтому востребован в оптоэлектронной и сенсорной технике [1-3].

Формирование слоев $\mathrm{PbSe}$ осуществляется, как правило, вакуумным испарением [1,4-7] и эпитаксиальными методами [8] Однако одним из наиболее перспективных способов считается химическое осаждение из водных сред [3,9-13]. Этот универсальный метод характеризуется простотой организации, однородностью получаемых тонкопленочных покрытий, управляемостью процесса и возможностью регулирования электрофизическими свойствами. Известно $[3,9,12,13]$, что использование селеномочевины обеспечивает получение пленок $\mathrm{PbSe}$ с более высокими фотоэлектрическими характеристиками по сравнению с другими халькогенизаторами, однако ее особенностью, затрудняющей ее применение, является высокая склонность к окислению в водных растворах. Основным путем решения этой проблемы является введение в раствор селеномочевины антиоксидантов - веществ с высокой восстановительной способностью, в частности сульфита натрия
$\mathrm{Na}_{2} \mathrm{SO}_{3}$ [9,11-13]. Однако в этом случае пленки загрязняются серосодержащими примесями, что влияет на их фотоэлектрические характеристики. Одним из перспективных ингибиторов окисления селеномочевины, исходя из своего окислительно-восстановительного

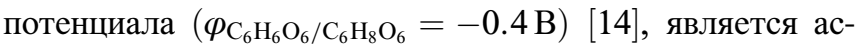
корбиновая кислота. Однако в литературе отсутствуют комплексные данные по влиянию этого антиоксиданта на морфологию, структурные и фотоэлектрические свойства пленок $\mathrm{PbSe}$.

Свежеосажденные пленки селенида свинца не обладают фотоответом к ИК-излучению. Для их сенсибилизации в большинстве случаев применяют термообработку, способствующую включению в состав слоя кислородсодержащих фаз $[3,12,13,15]$. Улучшает функциональные свойства пленок использование также легирующих добавок, в частности иода, соединения которого либо добавляют в реакционную смесь при химическом осаждении $[9,12,13]$, либо термический отжиг селенида свинца проводят в его парах [3]. Учет поведения этой добавки, несомненно, чрезвычайно важен при целенаправленном получении слоев $\mathrm{PbSe}$ с высокими фотоэлектрическими характеристиками.

В настоящем исследовании предпринята комплексная попытка химического осаждения пленок $\mathrm{PbSe}$ с использованием в качестве ингибитора окисления селеномочевины аскорбиновой кислотой с целью изучения ее 
влияния на состав, морфологию, структурные и фотоэлектрические свойства селенида свинца.

\section{2. Методика эксперимента}

Пленки селенида свинца $\mathrm{PbSe}$ получали химическим осаждением из водных растворов, содержащих ацетат свинца $\mathrm{Pb}\left(\mathrm{CH}_{3} \mathrm{COO}\right)_{2}$, селеномочевину $\mathrm{CSe}\left(\mathrm{NH}_{2}\right)_{2}$, ацетат аммония $\mathrm{NH}_{4} \mathrm{CH}_{3} \mathrm{COO}$ и этилендиамин $\mathrm{H}_{2} \mathrm{NCH}_{2} \mathrm{CH}_{2} \mathrm{NH}_{2}$, выполняющих роль комплексообразующих агентов, а также легирующую добавку иодида аммония $\mathrm{NH}_{4} \mathrm{I}$. Раствор халькогенизатора готовили отдельно путем добавления навески селеномочевины в $0.0001 \mathrm{M}$ раствор аскорбиновой кислоты $\mathrm{C}_{6} \mathrm{H}_{8} \mathrm{O}_{6}$. После сливания реагентов реакционную смесь перемешивали, в нее во фторопластовом держателе погружали предварительно обезжиренные подложки из ситалла марки СТ-150-2 или матированного стекла с 14 классом чистоты. Синтез пленок осуществляли в жидкостном термостате „ТС-ТБ-10“ в течение 90 мин при $308 \mathrm{~K}$ с точностью поддержания температуры в нем $\pm 0.1 \mathrm{~K}$.

Толщину синтезированных пленок определяли при помощи микроинтерференционного микроскопа Линника МИИ-4М.

Термический отжиг слоев $\mathrm{PbSe}$ проводили в атмосфере воздуха в температурном диапазоне $633-683 \mathrm{~K}$ в муфельной печи типа ПИ-1.0-7 путем нагрева со скоростью 11 град/мин до рабочей температуры с последующим остыванием со скоростью 0.8 град/мин. Точность поддержания температуры в зоне размещения пленки составляла $\pm 2 \mathrm{~K}$.

Исследование структурно-морфологических характеристик и элементного состава пленок $\mathrm{PbSe}$ проводили методом растровой электронной микроскопии с использованием микроскопа MIRA 3 LMU при ускоряющем напряжении электронного пучка 15 кВ, а также растрового электронного микроскопа JEOLJSM-5900 LV с приставкой для энергодисперсионного анализа EDS Inca Energy 250.

Кристаллическую структуру и фазовый состав свежеосажденных и термообработанных пленок $\mathrm{PbSe}$ исследовали методом рентгеновской дифракции на дифрактометре ДРОН-4. Рентгенограммы снимали в медном излучении с применением пиролитического графита в качестве монохроматора для выделения $\mathrm{Cu} K_{\alpha 1,2}$-дублета из сплошного спектра в интервале углов от 15 до $100^{\circ}$ в режиме пошагового сканирования с $\Delta(2 \theta)=0.03^{\circ}$ и временем накопления сигнала в точке $7.2 \mathrm{c}$.

Оценку состава, степень окисления и валентное состояние элементов в полученных пленках проводили методом рентгеновской фотоэлектронной спектроскопии (XPS). Для исследования профилей распределения примесей по глубине осуществляли ионное травление аргоновым пучком поверхностных слоев. Анализ выполняли на электронном спектрометре ESCALAB MK II c использованием немонохроматического рентгеновского излучения $\operatorname{Mg} K_{\alpha}(1253.6$ эВ).
Изучение оптических свойств пленок $\mathrm{PbSe}$, осажденных на матированное стекло, проводили на спектрофотометре UV-3600 Shimadzu, оснащенном приставкой ISR-3100 с интегрирующей сферой. Съемку спектров светопропускания $T(\lambda)$ и диффузного отражения $R(\lambda)$ осуществляли в диапазоне длин волн 200-2500 нм с шагом 2 нм.

Полученные значения $T$ и $R$ использовали для вычисления коэффициента поглощения пленок $\alpha$ по формуле

$$
\alpha=\frac{1}{d} \ln \frac{(1-R)^{2}}{T}
$$

где $d$ - толщина пленки.

Для исследования фоточувствительных свойств пленок селенида свинца на их основе изготавливали чувствительные элементы $5 \times 5$ и $2 \times 2$ мм с электрохимически нанесенными омическими никелевыми контактами. Измерение фотоэлектрических характеристик синтезированных пленок проводили на специализированном стенде К.54.410 с источником ИК-излучения АЧТ $573 \mathrm{~K}$ при облученности чувствительного элемента $1 \cdot 10^{-4} \mathrm{BT} / \mathrm{cm}^{2}$, частоте модуляции излучения 800 Гц и напряжении смещения 50 В. Фотоотклик регистрировали в виде падения напряжения на согласованном нагрузочном сопротивлении.

Низкотемпературные исследования электропроводности, темнового сопротивления, вольт-ваттной чувствительности и шумов селенида свинца проводили в вакууме с остаточным давлением 0.1 Па в интервале температур 213-333 К. Охлаждение чувствительных элементов осуществляли с помощью термоэлектрического охладителя, работающего на эффекте Пельтье.

\section{3. Результаты и обсуждение}

Объектами исследований в работе являлись химически осажденные зеркальные пленки $\mathrm{PbSe}$ толщиной $300 \pm 30$ нм, имеющие хорошую адгезию к подложкам из ситалла и матированного стекла.

Локальный элементный анализ, проведенный в 10 точках свежеосажденной пленки $\mathrm{PbSe}$, свидетельствует о том, что она состоит в основном из свинца и селена, содержание которых составляет $49.7 \pm 3.1$ и $47.9 \pm 3.0 \mathrm{aT} \%$, а также содержит в среднем $2.4 \pm 0.2$ ат\% иода (см. таблицу). Соотношение между $\mathrm{Pb}$ и $\mathrm{Se}$ в слое практически соответствует стехиометрии (1.04). После отжига при $653 \mathrm{~K}$ соотношение между основными элементами в пленках увеличилось до 1.28 раза, т.е. по сравнению с халькогеном $(19.0 \pm 1.2)$ появился значительный избыток свинца $(24.4 \pm 1.5)$. При этом наблюдается небольшое увеличение средней концентрации иода от $2.4 \pm 0.2$ до $3.7 \pm 0.3 \mathrm{aT} \%$, обусловленное его неравномерным распределением по поверхности пленки: в некоторых областях этот элемент отсутствует, в других происходит его концентрирование до $9.8 \pm 0.8$ ат\%. Обращает на себя внимание 

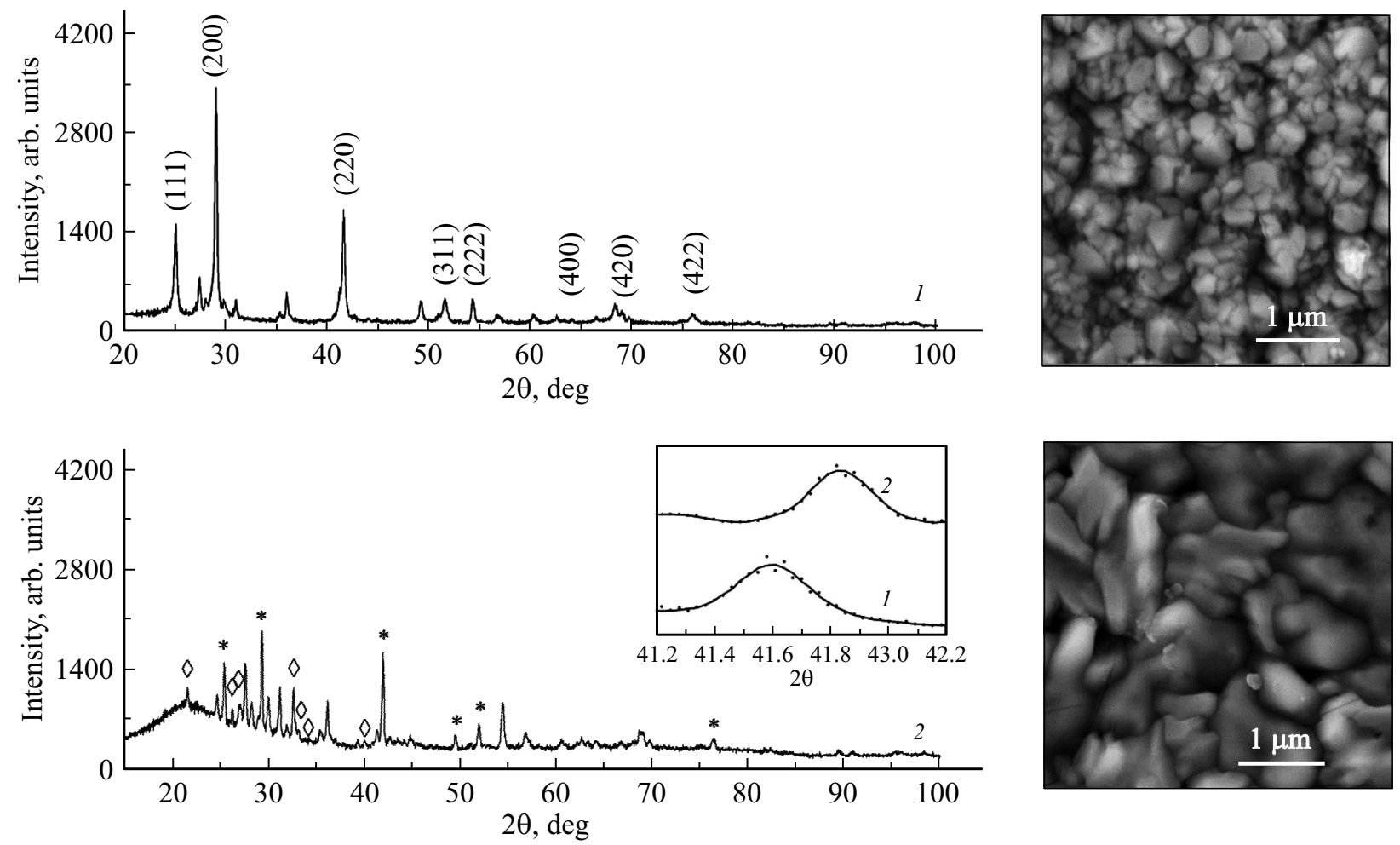

Рис. 1. Рентгенограммы и микроизображения свежеосажденных (1) и отожженных при температуре $653 \mathrm{~K}$ (2) пленок PbSe. На рентгенограмме отмечены рефлексы фазы $\mathrm{PbSe}$. Не отмеченные рефлексы на рентгенограмме свежеосажденной пленки относятся к материалу ситалловой подложки. На рентгенограммах отожженных пленок указаны рефлексы фаз $\mathrm{PbSe}, \mathrm{PbSeO} 3(\diamond)$, $\mathrm{PbSeO}_{4}(*)$. На вставке показано изменение положения дифракционного отражения (220) пленки $\mathrm{PbSe}$.

большое количество кислорода в составе пленок (до $52.9 \pm 3.3$ ат\%) за счет образования примесных кислородсодержащих фаз свинца.

Микроизображения и рентгенограммы свежеосажденной и термообработанной при $653 \mathrm{~K}$ пленок $\mathrm{PbSe}$ приведены на рис. 1. Так, микроизображения обсуждаемых пленок убедительно демонстрируют протекание в них процесса рекристаллизации: кристаллиты свежеосажденной нанопленки $\mathrm{PbSe}(50-80$ нм), имеющие форму сложных многогранников и усеченных пирамидок, превратились в неоднородные по форме поликристаллиты со средними размерами $0.1-0.8$ мкм.
Стоит отметить, что после отжига пленок соотношения интенсивностей дифракционных отражений присутствующих на рентгенограммах основной и примесных фаз отличаются друг от друга, что указывает на различие в их количественном содержании в составе слоя. Тем не менее преимущественной фазой является кубический $\mathrm{PbSe}$ со структурой $B 1$ (пр.гр. $F m \overline{3} m$ ) (PDF Card N 03-065-0133), дифракционные отражения (111), (200), (220) и (311) которой явно выделяются на фоне остальных рефлексов. Аппроксимация дифракционных отражений функцией псевдо-Фойгта позволила определить положение каждого отражения и найти период кри-

Элементный состав и структурные характеристики свежеосажденных и термообработанных при $653 \mathrm{~K}$ пленок PbSe

\begin{tabular}{c|c|c}
\hline Параметр & Свежеосажденные & Термообработанные \\
& пленкиенки
\end{tabular}




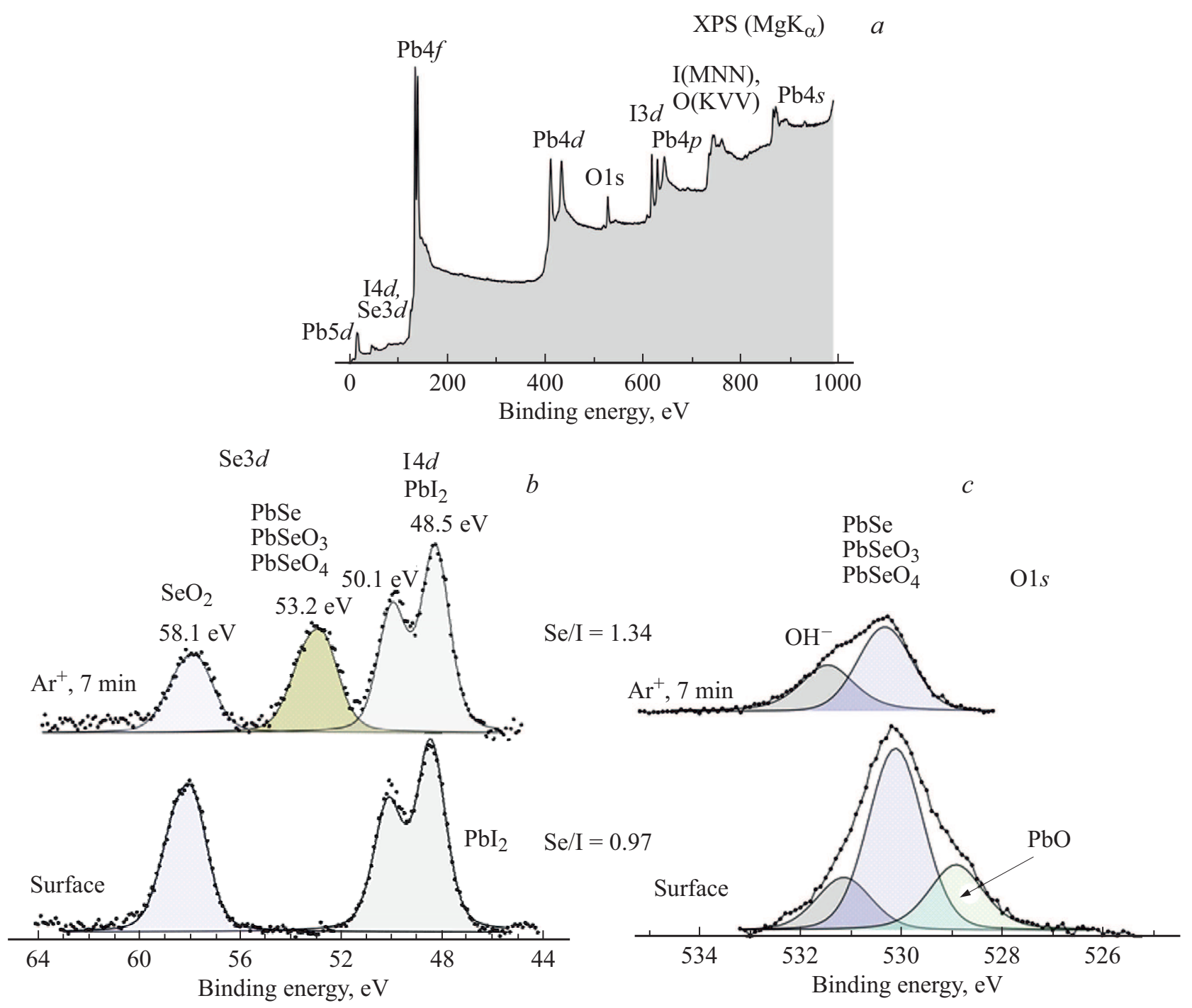

Рис. 2. XPS-спектры поверхности пленки PbSe после отжига при $653 \mathrm{~K}: a-$ обзорный спектр после $\mathrm{Ar}^{+}$-травления поверхности (7 мин); $b$ и $c-$ спектры I $4 d$, $\mathrm{Se} 3 d$ и O $1 s$ поверхности и после ионного травления в течение 7 мин.

сталлической решетки $\mathrm{PbSe}$. Уменьшение периода кристаллической решетки свежеосажденной пленки $\mathrm{PbSe}$ с $0.6129(8)$ до $0.6106(5)$ нм после отжига сопровождается значительным снижением микронапряжений: от $0.21 \pm 0.02$ до $0.10 \pm 0.01 \%$. Этот факт был установлен ранее авторами публикаций [16-19]. Изменение периода решетки после отжига приводит к смещению максимума дифракционных отражений, показанному на рис. 1 на примере грани (220), и заметному их сужению за счет структурной релаксации и перекристаллизации наночастиц. В результате отмечается изменение преимущественной ориентации кристаллитов фазы $\mathrm{PbSe}$ с направления роста [200] на [111] и уменьшение коэффициента текстурированности от $0.61 \pm 0.04$ до $0.31 \pm 0.02$ (см. таблицу).

Уменьшение периода кристаллической решетки, вероятно, связано с диффузией атомов иода к межфазной границе кристаллитов в процессе термической перекристаллизации. При этом происходит окисление об- разовавшегося иодида свинца до его оксидов. В итоге замещение более крупного атома иода I $(r=0.22$ нм) на меньший по размеру кислород $\mathrm{O}(r=0.14$ нм $)$ способствует уплотнению структуры и уменьшению длины связей между узлами кристаллической решетки.

В результате термического окисления селенида свинца установлено образование новых фаз (селенита $\mathrm{PbSeO}_{3}$ и селената $\mathrm{PbSeO}_{4}$ ), дифракционные отражения которых отмечены на рентгенограммах (рис. 1), и, возможно, оксидов свинца, не обозначенных на дифрактограмме из-за перекрывания их рефлексами подложки и оксиселенитных фаз. Из-за слабой интенсивности дифракционных отражений можно предположить, что фаза оксида свинца образуется локально в виде включений небольших размеров, формирование которых возможно за счет катализирующего действия иода на процесс окисления, либо в местах спонтанного скопления кислорода, вызванного уменьшением межзеренной поверхности кристаллитов в результате перекристаллизации. 

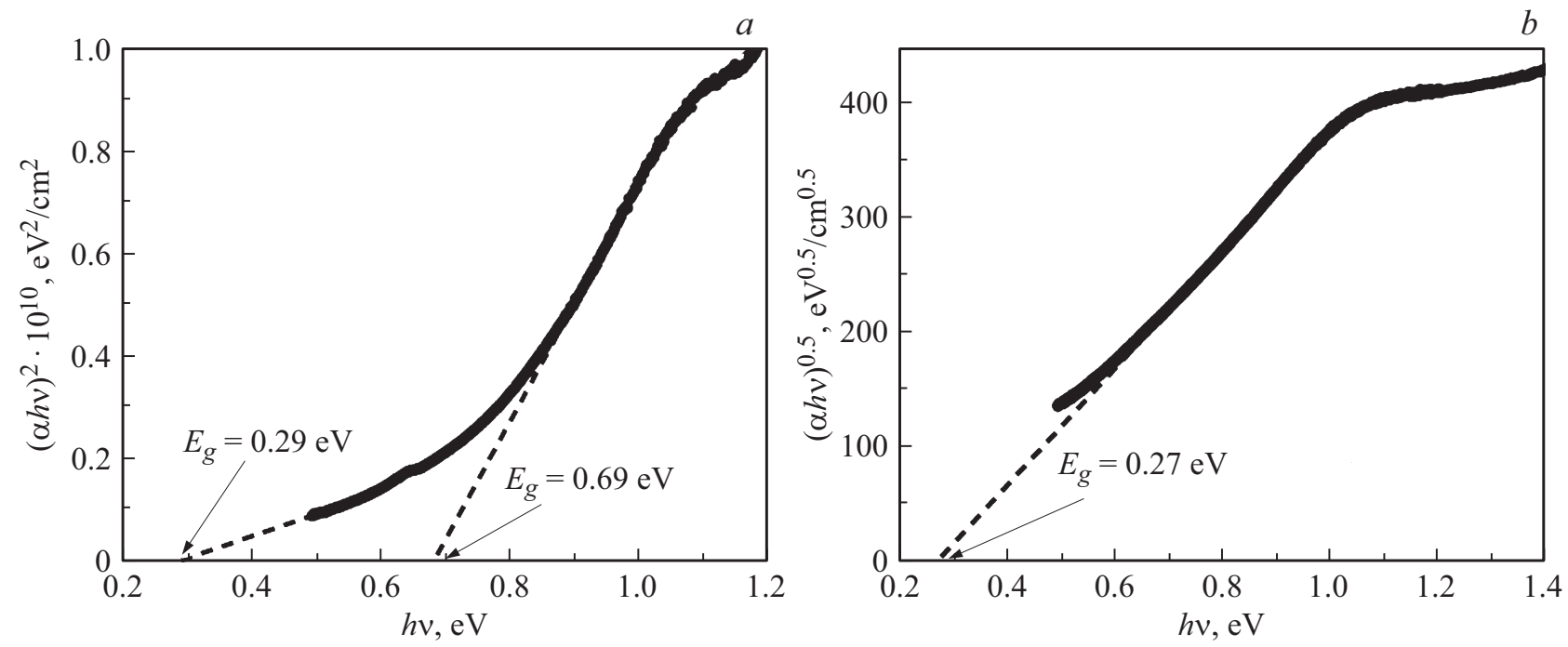

Рис. 3. Графическое определение оптической ширины запрещенной зоны $E_{g}$ теромообработанных при $653 \mathrm{~K}$ пленок $\mathrm{PbSe}$, осажденных на матированное стекло, при прямом $(a)$ и непрямом $(b)$ переходах.

Для получения более достоверных сведений о положении кислорода и иода в структуре пленки $\mathrm{PbSe}$ после отжига при $653 \mathrm{~K}$ была проведена рентгеновская фотоэлектронная спектроскопия приповерхностных слоев до и после их травления в течение 7 мин ионами аргона $\mathrm{Ar}^{+}$.

На обзорном спектре пленки после 7 мин травления поверхности ионами $\mathrm{Ar}^{+}$(рис. 2, $a$ ) доминируют линии $\mathrm{Pb} 4 f$-свинца и I $4 d$-иода, также присутствуют максимумы от O $1 s$-кислорода и $\mathrm{Se} 3 d$-селена. Показателен участок XPS-спектра в области 44-64 эВ (рис. 2, b), где располагаются линии I $4 d$-иода и $\mathrm{Se} 3 d$-селена. Видно, что на поверхности пленки селен находится исключительно в формеоксида $\mathrm{SeO}_{2}$, этому состоянию $\mathrm{Se}$ отвечает максимум при 58.1 эВ [20]. Энергия связи линий $\mathrm{I} 4 d$-иода указывает на иодид свинца $\mathrm{PbI}_{2}[21]$. В спектре О $1 s$-кислорода поверхности (рис. 2,b) присутствуют составляющие от $\mathrm{SeO}_{2}$ и $\mathrm{PbO}$. Также на поверхности присутствуют сорбированные формы гидроксида $\mathrm{OH}^{-}$. После 7 мин ионного травления максимум от $\mathrm{PbO}$ в спектре О $1 s$-кислорода полностью исчезает и снижается интенсивность полосы, которую мы связываем с $\mathrm{SeO}_{2}$, а полоса $\mathrm{PbSe}\left(\mathrm{PbSeO}_{3}, \mathrm{PbSeO}_{4}\right)$, напротив, усиливается. В спектре $\mathrm{Se} 3 d$-селена (рис. 2,b) интенсивность полосы $\mathrm{SeO}_{2}$ также снижается и появляется максимум при 53.2эВ. Последний отнесен нами к $\mathrm{PbSe}[22] \mathrm{c}$ долей вероятности присутствия соединений $\mathrm{PbSeO} 3$ или $\mathrm{PbSeO} 4$. Соотношение $\mathrm{Se} / \mathrm{I}$ возрастает от 0.97 до 1.34 по мере удаления от межфазной поверхности пленки после 7 мин ее травления аргоновым пучком.

Таким образом, результаты XPS показывают, что на поверхности пленки $\mathrm{PbSe}$ после отжига на воздухе при $653 \mathrm{~K}$ присутствует тонкий слой $\mathrm{PbO}$. Далее следуют фазы $\mathrm{SeO}_{2}$ и $\mathrm{PbI}_{2}$, которые постепенно замещаются объемной фазой $\mathrm{PbSe}$ и оксидными формами $\mathrm{PbSeO}_{3}$ и $\mathrm{PbSeO}_{4}$, на которые указывает РФА.
По результатам проведенных оптических исследований было установлено значение коэффициента поглощения $\alpha$ (при $\lambda \sim 1000 \mathrm{Hм}$ ), равное $2.7 \cdot 10^{5} \mathrm{~cm}^{-1}$. Полученные значения $\alpha(\lambda)$ использовали для определения оптической ширины запрещенной зоны $E_{g}$ в случае прямых и непрямых разрешенных межзонных переходов. Математическую обработку проводили исходя из существования следующей зависимости между $\alpha$ и $E_{g}$ :

$$
[\alpha h v]^{1 / n}=A \cdot\left(h v-E_{g}\right),
$$

где $h v-$ энергия фотонов, $A-$ коэффициент, зависящий от пропускающей способности пленки и ее толщины, $E_{g}$ - оптическая ширина запрещенной зоны, $n$ - показатель степени, равный 0.5 для случая прямых разрешенных межзонных переходов либо 2 для случая непрямых разрешенных межзонных переходов. Таким образом, величина оптической щели может быть определена путем экстраполяции линейных участков двух функций: $[\alpha h v]^{2}=f(h v)$ и $[\alpha h v]^{0.5}=f(h v)$ на ось абсцисс.

На рис. 3 приведены результаты графического определения оптической ширины запрещенной зоны для пленки $\mathrm{PbSe}$, осажденной в присутствии $\mathrm{C}_{6} \mathrm{H}_{8} \mathrm{O}_{6}$ на матированное стекло. В результате экстраполяции двух прямолинейных участков, обнаруженных на полученных зависимостях в области наименьших энергий фотонов, были определены близкие значения $E_{g}: 0.29$ (рис. 3, $a$ ) и 0.27 эВ (рис. 3, $b$ ). Полученные величины хорошо согласуются с ранее опубликованными результатами квантово-химических расчетов ширины запрещенной зоны и экспериментально определенными значениями $E_{g}$ для $\mathrm{PbSe}$, измеренными при комнатной температуре [23]. Однако при рассмотрении функции $[\alpha h v]^{2}=f(h v)$ (рис. 3,a) был выделен еще один участок в диапазоне $0.85-1.0$ эВ с $E_{g}=0.69$ эВ, который можно 
объяснить вкладом в измеряемую величину широкозонных примесных фаз $\left(\mathrm{PbSeO}_{3}, \mathrm{PbSeO}_{4}, \mathrm{PbI}_{2}, \mathrm{PbO}\right)$.

Следует отметить, что в научной литературе мало сведений о формировании энергетического зазора в гетерофазных тонкопленочных структурах на основе селенида свинца. Исследователями, как правило, рассматриваются гомогенные структуры и зависимость величины $E_{g}$ от размера кристаллитов либо от количества внедренных примесей.

Как было показано в [23,24], присутствие определенного количества кислородсодержащих фаз $\left(\mathrm{PbSeO}_{3}\right.$, $\left.\mathrm{PbSeO}_{4}, \mathrm{PbO}\right)$, образующихся при термообработке, способствует сенсибилизации пленок PbSe. Механизм их действия основан на формировании в запрещенной зоне селенида свинца акцепторных уровней и оптимизации концентрации носителей заряда.

Как видно из рис. 4, зависимость вольтовой чувствительности $U_{S}$ пленок $\mathrm{PbSe}$ к ИК-излучению от температуры отжига носит экстремальный характер с максимумом в области $658 \mathrm{~K}$, т.е. с повышением температуры отжига до этих значений происходит увеличение вольтовой чувствительности слоев (кривая 1). Дальнейший рост температуры отжига приводит к снижению вольтовой чувствительности, связанному, вероятно, с так называемым переокислением пленок за счет увеличения содержания в них кислородсодержащих фаз, что сопровождается уменьшением концентрации и подвижности носителей заряда.

Свежеосажденные слои $\mathrm{PbSe}$ обладают темновым сопротивлением $R_{T}$ в мегаомном диапазоне. Как видно из рис. 4, в интервале температур от 643 до $675 \mathrm{~K}$ происходит снижение темнового сопротивления пленок с 1500 до 670 кОм, т. е. более чем 2.2 раза. Это является следствием процессов их рекристаллизации и упорядочения структуры. Дальнейшее повышение температуры отжига приводит к постепенному росту $R_{T}$ (кривая 2 ).

Важную информацию о свойствах полученных пленок $\mathrm{PbSe}$ дают низкотемпературные исследования их фотоэлектрических характеристик в интервале $213-300 \mathrm{~K}$ : темнового сопротивления $R_{T}$, вольт-ваттной чувствительности $S_{U}$ и шумов $N$. Их результаты показаны на рис. 5 в виде зависимостей, нормированных на соответствующие значения при $300 \mathrm{~K}$.

Так, вольт-ваттная чувствительность исследованных чувствительных элементов $2 \times 2$ мм при охлаждении до $213 \mathrm{~K}$ повышается до $\sim 1700 \mathrm{~B} / \mathrm{B}$, т.е. в 13 раз по сравнению с проведенными измерениями при $T=300 \mathrm{~K}$, при одновременном сохранении относительно низкого уровня шумов и росте темнового сопротивления в $\sim 7$ раз. Следует отметить, что, исходя из выявленной зависимости темнового сопротивления от температуры, введение аскорбиновой кислоты снижает величину механических напряжений, возникающих из-за различий в коэффициентах термического расширения на интерфейсе „пленка-подложка“, за счет повышения эластичности межфазного слоя. Отметим, что исследуемые в работе чувствительные элементы на основе отожженных

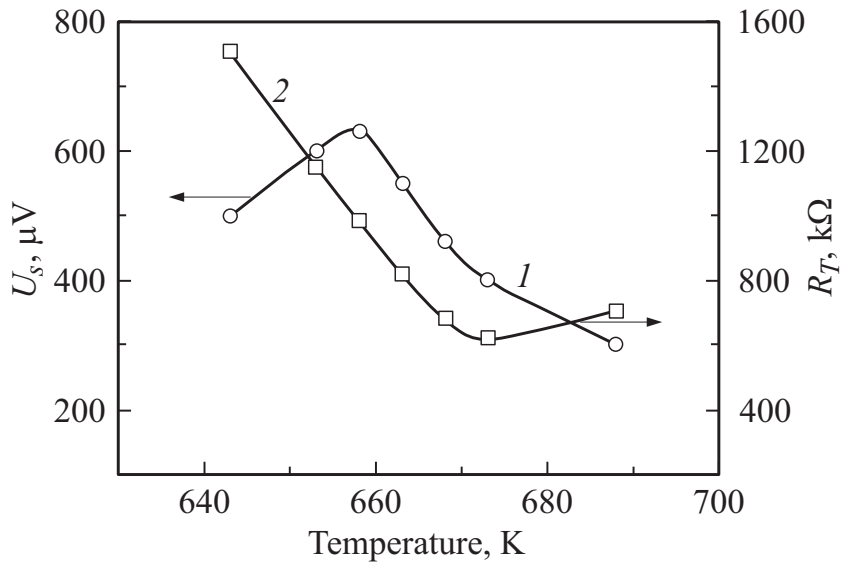

Рис. 4. Изменение вольтовой чувствительности $U_{S}(1)$ и темнового сопротивления $R_{T}(2)$ элементов $5 \times 5$ мм на основе пленок $\mathrm{PbSe}$ от температуры отжига.

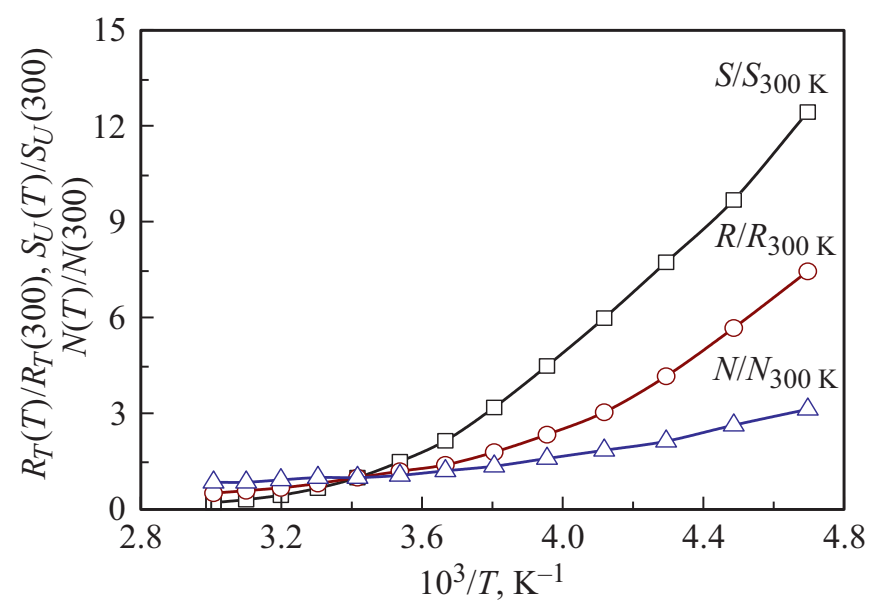

Рис. 5. Температурные зависимости отношений темнового сопротивления $R_{T}$, вольт-ваттной чувствительности $S_{U}$ и шумов $N$ чувствительных элементов $(2 \times 2$ мм $)$ на основе $\mathrm{PbSe} \kappa$ их значениям при $T=300 \mathrm{~K}$.

пленок $\mathrm{PbSe}$ обладают также относительно высокой обнаружительной способностью, достигающей при $213 \mathrm{~K}$ $4 \cdot 10^{8} \mathrm{BT}^{-1} \cdot \Gamma_{ц}{ }^{-1 / 2} \cdot \mathrm{cм}$, что сопоставимо с широко используемыми на практике детекторами ИК-излучения на основе селенида свинца [25].

Таким образом, пленки $\mathrm{PbSe}$, синтезированные с использованием в качестве антиоксиданта селеномочевины аскорбиновой кислоты, обладают при относительно низких температурах высокой вольт-ваттной чувствительностью и обнаружительной способностью, что обеспечивает перспективу их использования в различных фотоприемных устройствах среднего ИК-диапазона.

\section{4. Заключение}

Изучены фазовый и элементный состав, структурные характеристики и фотоэлектрические свойства термооб- 
работанных при 633-683 K в атмосфере воздуха пленок $\mathrm{PbSe}$, осажденных в присутствии аскорбиновой кислоты, используемой в качестве антиоксиданта селеномочевины. Оптическая ширина запрещенной зоны $E_{g}$ слоев, полученных на матированном стекле пленок, составила при непрямом энергетическом переходе 0.27 эВ, а при прямом переходе 0.29 и 0.68 эВ. Значения вольт-ваттной чувствительности изготовленных на основе $\mathrm{PbSe}$ чувствительных элементов при относительно низких температурах $(213 \mathrm{~K})$ сопоставимы с известными коммерческими образцами. Полученные результаты создают возможность их широкого практического использования для изготовления высокочувствительных ИК-KUKD детекторов, поглощающих слоев преобразователей излучения и термоэлектрических устройств.

\section{Финансирование работы}

Работа выполнена при финансовой поддержке программы 211 Правительства Российской Федерации № 02.A03.21.0006, гранта РФФИ 20-48-660041 р_а и в рамках планового задания А-19-1190318.90025-9 и государственного задания ФАНО России (тема „Поток“ № AAAA-A18-118020190112-8).

\section{Конфликт интересов}

Авторы заявляют, что у них нет конфликта интересов.

\section{Список литературы}

[1] L. Hu, S. Huang, R. Patterson, J.E. Halpert. J. Mater. Chem. C, 7, 4497 (2019).

[2] Z. Chen, Z. Zhang, J. Yang, W. Chen, Z.L. Teh, D. Wang, L. Yuan, J. Zhang, J.A. Stride, G.J. Conibeer, R.J. Patterson, S. Huang. J. Mater. Chem. C, 6, 9861 (2018).

[3] M.-H. Jang, P.M. Litwin, S.-S. Yoo, S.J. Mc Donnell, N.K. Dhar, M.C. Gupta. J. Appl. Phys., 126, 105701 (2019).

[4] X. Sun, K. Gao, X. Pang, H. Yang, A.A. Volinsky. Thin Sol. Films, 592, 59 (2015).

[5] S. Anwar, M. Pattanaik, B.K. Mishra, S. Anwar. Mater. Sci. Semicond. Process., 34, 45 (2015).

[6] Ch.-H. Huang, Y.-L. Jan, W.-J. Chuang, P.-T. Lu. Crystals, 8, 343. (2018). KU

[7] С.П. Зимин, И.И. Амиров. ФТП, 50, 1146 (2016).

[8] S. Wang, T. Shen, H. Bai, B. Li, J. Tian. J. Mater. Chem. C, 34, 8020 (2016).

[9] Z.I. Smirnova, L.N. Maskaeva, V.F. Markov, V.I. Voronin, M.V. Kuznetsov. J. Mater. Sci. Technol., 31, 790 (2015).

[10] Y. Wang, Y.-H. Liu, Y. Zhang, P.J. Kowalski, H.W. Rohrs, W.E. Buhro. Inorg. Chem., 52, 2933 (2013).

[11] Y. Suh, S.-H. Suh, S.Y. Lee, G.-H. Kim. Thin Sol. Films, 628, 148 (2017).

[12] З.И. Смирнова, В.М. Баканов, Л.Н. Маскаева, В.Ф. Марков, В.И. Воронин. ФТТ, 56 (12), 2468 (2014).

[13] Х.Н. Мухамедзянов, В.Ф. Марков, Л.Н. Маскаева. ФТП, 48 (2), 278 (2014)

[14] М. Девис, Дж. Остин, Д. Патридж. Витамин С: Химия и биохимия, пер. с англ. М.Б. Костиной (М., Мир, 1999) c. 147.
[15] P. Kumar, M. Pfeffer, C. Berthold, O. Eibl. J. Alloys Compd., 735, 1654 (2018).

[16] W. Feng, J. Song, Y. Ren, L. Yi, J. Hu, R. Zhu, H. Dong. Physica E: Low-Dimensional Systems and Nanostructures, 102, 153 (2018).

[17] W. Feng, J. Song, Y. Ren, F. Chen, J. Hu, S. Yu, H. Zhao, Y. Tang, S. Huang. J. Alloys Compd., 770, 649 (2019).

[18] K.C. Preetha T.L. Remadevi. Mater. Sci. Semicond. Process., 16, 605 (2013).

[19] S.A. Bashkirov, V.F. Gremenoka, V.A. Ivanov, K. Bente, P.P. Gladyshev, T.Yu. Zelenyak, A.M. Saad, M.S. Tivano. Thin Sol. Films, 616, 773 (2016).

[20] L.L. Kazmerski, O. Jamjoum, P.J. Ireland, S.K. Deb, R.A. Mickelsen, W. Chen. J. Vac. Sci. Technol., 19, 467 (1981).

[21] S.M. Jain, B. Philippe, E.M.J. Johansson, B. Park, H. Rensmo, T. Edvinsson, G. Boschloo. J. Mater. Chem. A, 4 (7), 2630 (2016).

[22] Y.X. Ren, T.J. Dai, W.B. Luo. Vacuum, 149, 190 (2018).

[23] Ch.E. Ekuma, D.J. Singh, J. Moreno, M. Jarrell. Phys. Rev. B, 85, 085205 (2012).

[24] G.L. Agawane, S.W. Shin, M.P. Suryawanshi, K.V. Gurav, A.V. Moholkar, J.Y. Lee, P.S. Patil, J.H. Yun, J.H. Kim. Mater. Lett., 106, 186 (2013).

[25] В.В. Матюхин, Д.Г. Паринов, Е.А. Татаринова. Прикл. физика, 6, 60 (2017).

Редактор Г.А. Оганесян

\section{Structure and photoelectric properties of $\mathrm{PbSe}$ films deposited in the presence of ascorbic acid}

\author{
L.N. Maskaeva ${ }^{\mathbf{1 , 2}}$, V.M. Yurk ${ }^{\mathbf{1}}$, V.F. Markov ${ }^{\mathbf{1 , 2}}$, \\ M.V. Kuznetsov ${ }^{3}$, V.I. Voronin ${ }^{4}$, O.A. Lipina], ${ }^{3}$ \\ ${ }^{1}$ Ural Federal University named \\ after the first President of Russia B.N. Yeltsin, \\ 620002 Yekaterinburg, Russia \\ 2 Ural State Fire Service Institute \\ of Emergency Ministry of Russia, \\ 620022 Yekaterinburg, Russia \\ ${ }^{3}$ Institute of Solid State Chemistry, \\ Ural Branch of Russian Academy of Sciences, \\ 620990 Yekaterinburg, Russia \\ ${ }^{4}$ Miheev Institute of Metal Physics of Ural Branch \\ of Russian Academy of Sciences, \\ 620108 Yekaterinburg, Russia
}

\begin{abstract}
PbSe thin films chemically deposited using ascorbic acid as an antioxidant for selenourea were examined by $X$-ray diffraction (XRD), scanning electron microscopy (SEM) with $X$-ray microanalysis (EDX) and $X$-ray photoelectron spectroscopy (XPS). Influence of annealing temperature on chemical and phase composition, lattice parameters, surface morphology and photoelectric properties were studied. Determined that $\mathrm{PbSe}$ thin films contain dopant phase $\mathrm{PbSeO}_{3}, \mathrm{PbSeO}_{4}, \mathrm{PbI}_{2}$ after annealing at $633-683 \mathrm{~K}$. The direct and indirect optical band gaps $E_{g}$ layers were observed. It has been shown that the deposited films are comparable with known commercial samples by their threshold photoelectric characteristics and can be used to create highly sensitive IR detectors.
\end{abstract}

